\title{
Aplikasi Pencari Lokasi Ukm Di Tembalang Menggunakan Location Based Service
}

Iqoniyoma Faundra, Rinta Kridalukmana*), Ike Pertiwi Windasari

Program Studi Sistem Komputer, Fakultas Teknik, Universitas Diponegoro

Jl. Prof. Soedarto, SH, Kampus Undip Tembalang, Semarang, Indonesia 50275

\begin{abstract}
SMEs (Small-Medium Enterprises) is the one of economical meters in Indonesia. Research step in designing the application is to determine of main problem and purpose, analysis which covering general description, functional and non-functional need. Android base aplication to search UKM Tembalang which made for searching SMEs location, and give more information about SMEs business. UKM Tembalang is a client server base aplication which made by using java programing language with eclipse software and MySQL database. Location data will be save in database which focusing on taking coorndinate that use GPS to get map and Google Maps APIs for get the route. The use of Google Maps API service and GPS make the aplication better in taking the location coordinate.beside that, the aplication also get for searching position SMEs in Tembalang, with the aplication location searching SMEs.
\end{abstract}

Keywords - SMEs; Android; Location Based Service (LBS); MySQL; GPS

Abstrak - UKM (Usaha Kecil Menengah) merupakan salah satu tombak perekonomian di Indonesia Aplikasi Pencari Lokasi UKM Tembalang Berbasis Android yang dibuat untuk pencarian lokasi UKM dan memberi informasi lebih tentang sebuah usaha. UKM Tembalang merupakan aplikasi berbasis client server yang dibuat dengan menggunakan bahasa pemrograman java dengan software eclipse dan menggunakan basisdata MySQL. Data lokasi kafe akan disimpan dalam basisdata yang dititik beratkan pada pengambilan koordinat yang memanfaatkan GPS untuk mendapatkan peta dan Google Maps APIs untuk mendapatkan rute. Penggunaan layanan Google Maps API dan GPS menjadikan aplikasi menjadi lebih baik dalam pengambilan koordinat lokasi. Selain itu aplikasi ini juga dapat mencari letak lokasi UKM di Tembalang, dengan adanya aplikasi pencari lokasi UKM, pengguna dapat dengan mudah menemukan UKM yang dinginkan, beserta informasi UKM yang diambil dari google maupun website dari UKM tersebut.

Kata kunci - UKM; Android; Location Based Service (LBS); MySQL; GPS

\section{Pendahuluan}

UKM merupakan singkatan dari Usaha Kecil Menengah, yang memiliki posisi penting dalam perekonomian di Indonesia. Pertumbuhan UKM pun semakin tinggi setiap

*) Penulis Korespondensi ( Rinta Kridalukmana)

Email: rintakrida@ce.undip.ac.id tahunnya $^{[1]}$. Namun, seiring dengan diberlakukannya AFTA (Asean Free Trade Area) mulai tanggal 1 Januari 2015 memberikan sedikit ancaman sekaligus peluang emas bagi para pelaku UKM di Indonesia khususnya di Semarang

Salah satu kelemahan dari UKM di Indonesia adalah kurangnya proses promosi dan pengenalan produk ke masyarakat luas, sehingga dikhawatirkan produk UKM akan kalah bersaing dengan banyaknya usaha dan produk yang masuk dari Negara lain sejak pemberlakuan AFTA dan MEA. Namun seiring perkembangan informasi dan teknologi, membuka kemungkinan untuk pelaku UKM mengenalkan produk dan usahanya ke masyarakat luas melalui aplikasi digital.

Penelitian membahas tentang Location Based Service (LBS) sudah banyak dilakukan, misalnya untuk aplikasi pencari lokasi wisata [2], pencari lokasi AM dan pom bensin[3], dan pencari tempat makan [4] serta transportasi bus [5]. Pada intinya untuk pengguna smartphone yang sudah mendukung GPS, pengguna dapat mengetahui posisinya saat itu juga dan mencari tempat tertentu dengan memanfaatkan teknologi ini. Location-Based Service (LBS) dengan memanfaatkan teknologi GPS dalam pengaplikasiannya. Selain dapat mengetahui posisi pengguna, aplikasi LBS juga dapat menentukan posisi tempat-tempat tertentu. Jika seorang pengguna dapat memaksimalkan teknologi ini maka akan memudahkan pengguna tersebut untuk mencari lokasi yang diinginkan tanpa harus kesulitan bertanya.

Masalah dan penelitian tentang LBS ini memunculkan ide untuk membuat Aplikasi pencarian lokasi UKM berbasis Android menggunakan bahasa pemrograman Java dengan software yang sesuai dan menggunakan database MySql untuk menyimpan data lokasi UKM di Tembalang[6]. Aplikasi ini dapat digunakan oleh pelaku UKM dengan menuntun pemilihan lokasi atau penuntun jalan menuju lokasi UKM tersebut, aktivitas yang dimaksud seperti melihat rute perjalanan menuju UKM tersebut.

Hasil yang diharapkan dari aplikasi pencari lokasi ini untuk membantu para pelaku UKM dan para konsumen khususnya mahasiswa menemukan lokasi-lokasi UKM tersebut di Tembalang.

Tujuan utama pada penelitian ini adalah untuk membangun sistem informasi dan aplikasi UKM Tembalang yang dapat digunakan untuk memberikan informasi tentang UKM dan lokasi dari UKM tersebut sehingga memudahkan UKM dalam menyampaikan promosinya.

\section{PERANCANGAN SISTEM}

Tahapan penelitian Sistem Pencari Lokasi UKM ini meliputi: 1) beberapa proses melakukan penelitian, mengumpulkan informasi, pengetahuan, wawasan untuk mendukung topik dari rancangan yang akan dibuat, 2) membuat rancangan sistem yang akan dikembangkan, 3) proses validasi dan verifikasi bahwa program atau aplikasi berjalan sesuai dengan yang diharapkan, dan 4) melakukan pengujian hasil penelitian yang berupa program atau aplikasi 
akan digunakan pada pengguna perangkat bergerak berbasis Android[7][8].

Permasalahan merupakan latar belakang untuk membangun sebuah sistem yang baru, seringkali perekayasa perangkat lunak kesulitan dalam menentukan apa saja yang harus dilakukan oleh sistem. Deskripsi layanan dan batasan merupakan kebutuhan bagi sistem dan proses menemukan, menganalisis, mendokumentasikan dan memeriksa layanan dan batasan ini disebut analisis kebutuhan. Analisis kebutuhan ini diperlukan agar sistem dapat mencapai tujuan yang diharapkan.

Analisis sistem yang telah dibuat diharapkan mampu berjalan sesuai dengan keinginan sebagai berikut.

a. Adanya fasilitas untuk mencari lokasi saat ini dengan koordinat GPS pada perangkat. Sehingga memudahkan pengguna untuk mengetahui keberadaan posisi dari pengguna dan posisi UKM. Aplikasi ini menggunakan GoogleMaps API[9][10].

b. Adanya fasilitas daftar dari UKM yang terstruktur sehingga pengguna dapat mengetahui jenis UKM, lokasi tanpa harus bertanya di sekitaran tembalang, dalam fasilitas tersebut juga terdapat gambar, dimana pengguna dapat melihat gambar-gambar mengenai kondisi dan fasilitas yang di sediakan UKM tersebut. Aplikasi menyediakan informasi yang dibutuhkan pengguna untuk menghubungi pemilik maupun manajemen dari UKM yang tercantum pada bagian informasi UKM.

c. Adanya fasilitas penunjuk arah yang dapat di gunakan pengguna untuk menuju ke lokasi UKM yang hendak dituju, dengan begitu pengguna yang tidak begitu mengenal Tembalang tidak akan bingung untuk mencari letak ataupun posisi UKM yang dituju.

Pada aplikasi UKM Tembalang melibatkan pengguna dan admin sebagai actor dalam penggunaan sistem, dimana pengguna dapat melihat dan menggunakan aplikasi pada perangkat, seperti melakukan pencarian UKM, atau melihat jarak antara pengguna dan lokasi UKM. Sedangkan seorang admin diperlukan untuk mengurus sistem dan mengelola webserver aplikasi, admin juga yang mengatur semua detail info yang ditampilkan oleh aplikasi. Usecase diagram aplikasi ini dapat dilihat pada Gambar 1.

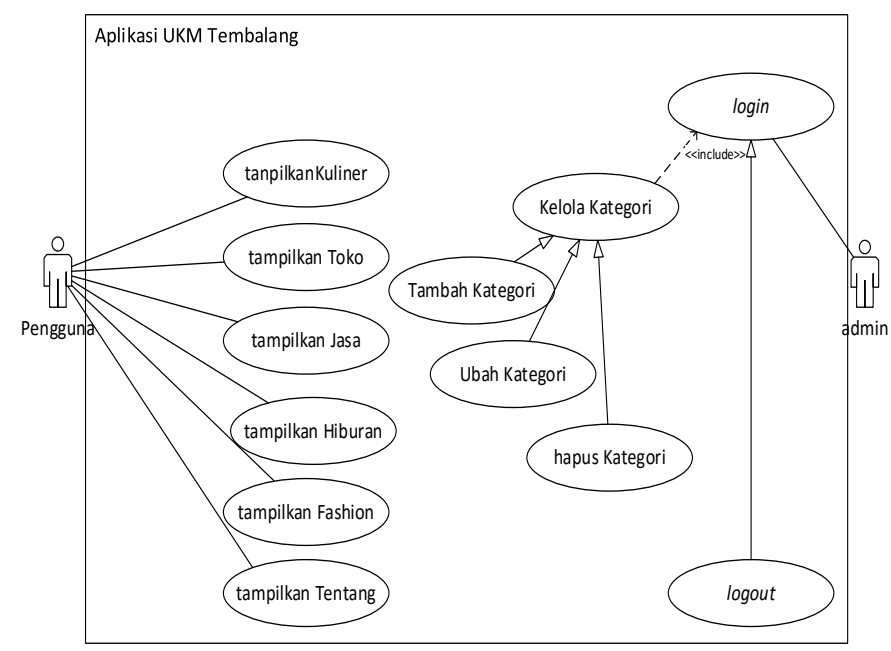

Gambar 1. Usecase Diagram

Activity Diagram menggambarkan berbagai alur aktivitas dalam sistem yang sedang dirancang serta bagaimana masing-masing alir berawal, decision yang mungkin terjadi, dan bagaimana mereka berakhir.

Activity Diagram juga dapat menggambarkan proses paralel yang mungkin terjadi pada beberapa eksekusi. Diagram menggambarkan berbagai alur aktifitas dalam sistem yang sedang dirancang.

Berikut merupakan beberapa diagram aktivitas yang terdapat pada perancangan aplikasi UKM Tembalang.

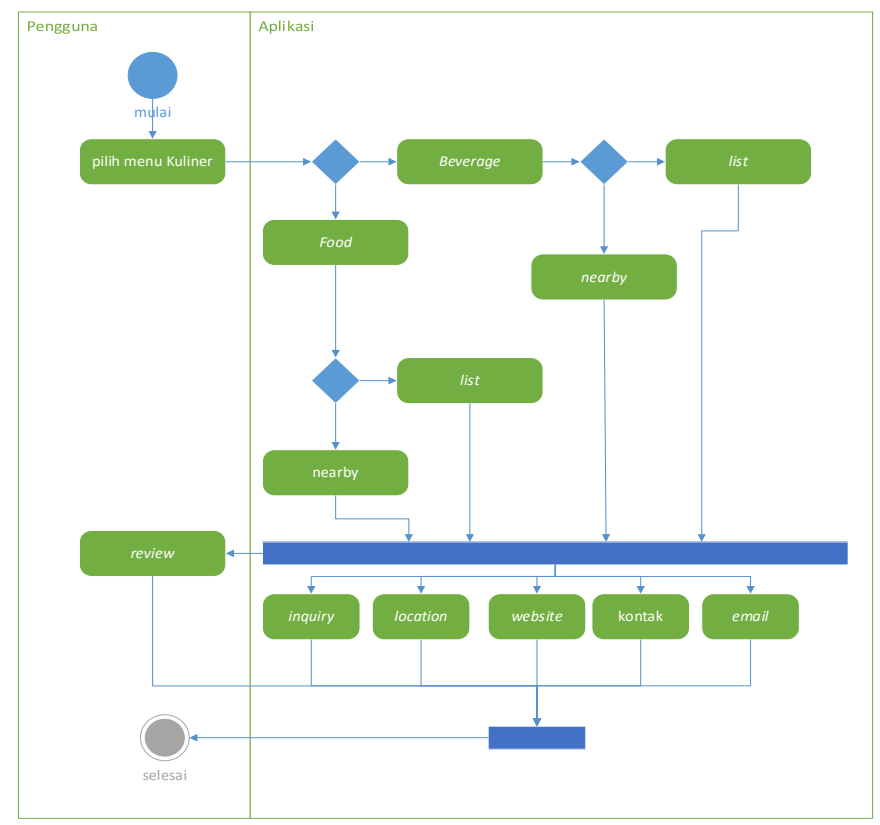

Gambar 2. Activity Diagram Kuliner

Pada Gambar 2 menggambarkan bagaimana proses yang terjadi ketika User Memilih Kuliner. Proses pertama yaitu pengguna akan memilih Kuliner, selanjutnya aplikasi akan menampilkan pilihan kategori food atau beverage, jika pengguna memilih pilihan food maka aplikasi akan menampilkan lagi pilihan kategori list dan nearby. Sedangkan jika pengguna memilih pilihan beverage maka aplikasi akan menampilkan juga pilihan kategori list dan nearby. Jika pengguna sudah memilih salah satu UKM maka aplikasi akan menampilkan about us berupa informasi ringkas tentang UKM tersebut dan menampilkan contact details dari UKM yang dipilih tersebut. Selanjutnya pengguna bisa memasukkan data inquiry yang berisi full name, contact No. , email, city dan message dan pengguna bisa mengirim atau menghapus data inquiry yang dimasukkan, selanjutnya jika pengguna memilih pilihan location maka aplikasi akan menampilkan lokasi UKM yang dipilih melalui GPS, selanjutnya jika pengguna memilih pilihan website maka aplikasi akan menampilkan website lokasi UKM yang dipilih melalui web browser, selanjutnya jika pengguna memilih pilihan melihat contact maka aplikasi akan menampilkan pilihan tindakan lengkap menggunakan kontak, telepon, dsb sesuai aplikasi yang mendukung pada perangkat pengguna. selanjutnya jika pengguna memilih pilihan email maka aplikasi akan menampilkan pilihan tindakan lengkap melalui aplikasi email yang mendukung pada perangkat pengguna dan pengguna bisa langsung mengirim pesan melalui email. Dan pengguna bisa memberikan reviews melalui pilihan add review maka aplikasi akan menampilkan form review berupa name, email, review dan memberi nilai berupa range bintang. 


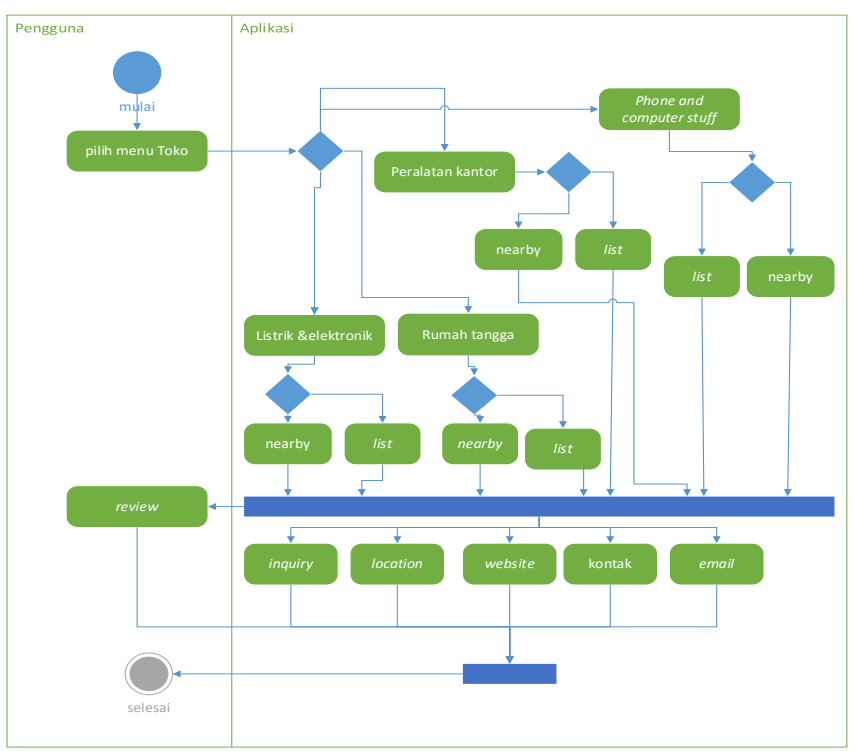

Gambar 3. Activity Diagram Toko

Pada Gambar 3 menggambarkan bagaimana proses yang terjadi ketika User Memilih Toko. Proses pertama yaitu pengguna akan memilih Toko, selanjutnya aplikasi akan menampilkan pilihan kategori Rumah tangga, listrik \& elektronik, Peralatan kantor atau Phone and computer stuff, jika pengguna memilih pilihan Rumah tangga maka aplikasi akan menampilkan lagi pilihan kategori list dan nearby. Jika pengguna memilih pilihan Listrik dan elektronik, Peralatan kantor maupun Phone and computer stuff maka aplikasi akan menampilkan juga pilihan kategori list dan nearby. Jika pengguna sudah memilih salah satu UKM maka aplikasi akan menampilkan about us berupa informasi ringkas tentang UKM tersebut dan menampilkan contact details dari UKM yang dipilih tersebut. Selanjutnya pengguna bisa memasukkan data inquiry yang berisi full name, contact No. , email, city dan message dan pengguna bisa mengirim atau menghapus data inquiry yang dimasukkan, selanjutnya jika pengguna memilih pilihan location maka aplikasi akan menampilkan lokasi UKM yang dipilih melalui GPS, selanjutnya jika pengguna memilih pilihan website maka aplikasi akan menampilkan website lokasi UKM yang dipilih melalui web browser, selanjutnya jika pengguna memilih pilihan melihat contact maka aplikasi akan menampilkan pilihan tindakan lengkap menggunakan kontak, telepon, dsb sesuai aplikasi yang mendukung pada perangkat pengguna. selanjutnya jika pengguna memilih pilihan email maka aplikasi akan menampilkan pilihan tindakan lengkap melalui aplikasi email yang mendukung pada perangkat pengguna dan pengguna bisa langsung mengirim pesan melalui email. Dan pengguna bisa memberikan reviews melalui pilihan add review maka aplikasi akan menampilkan form review berupa name, email, review dan memberi nilai berupa range bintang.

Pada Gambar 4 menggambarkan bagaimana proses yang terjadi ketika User Memilih Jasa. Proses pertama yaitu pengguna akan memilih Jasa, selanjutnya aplikasi akan menampilkan pilihan kategori Konveksi dan merchandise, Salon dan beauty clinic, Pengetikan \& fotocopy, Bengkel, atau Barbershop, jika pengguna memilih pilihan Konveksi dan merchandise maka aplikasi akan menampilkan lagi pilihan kategori list dan nearby.

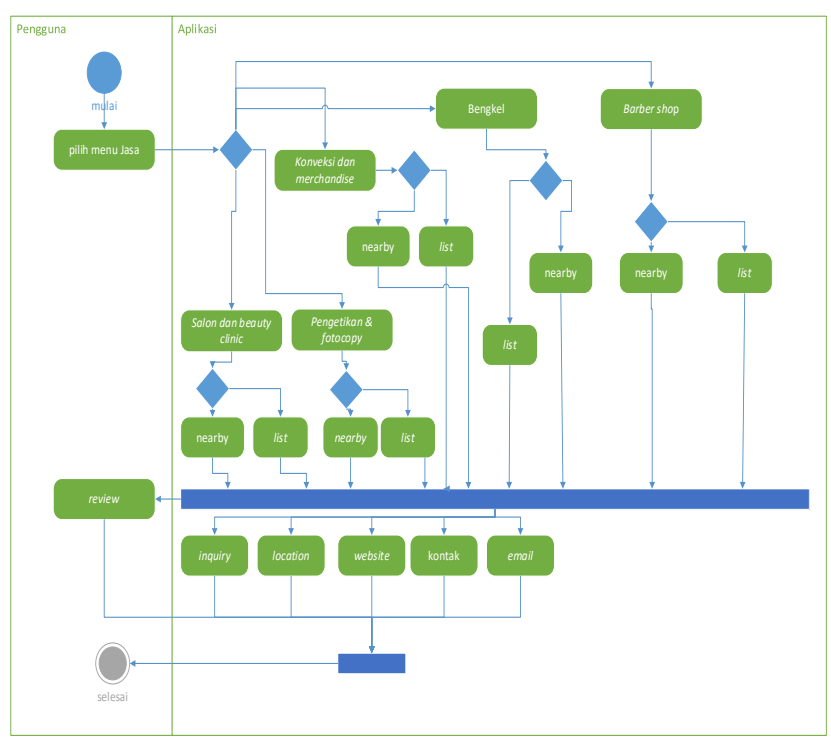

Gambar 4. Activity Diagram Jasa

Begitu pula jika pengguna memilih pilihan Konveksi dan merchandise, Salon dan beauty clinic, Pengetikan \& fotocopy, Bengkel, atau Barbershop, maka aplikasi akan menampilkan juga pilihan kategori list dan nearby. Jika pengguna sudahmemilih salah satu UKM maka aplikasi akan menampilkan about us berupa informasi ringkas tentang UKM tersebut dan menampilkan contact details dari UKM yang dipilih tersebut. Selanjutnya pengguna bisa memasukkan data inquiry yang berisi full name, contact No. , email, city dan message dan pengguna bisa mengirim atau menghapus data inquiry yang dimasukkan, selanjutnya jika pengguna memilih pilihan location maka aplikasi akan menampilkan lokasi UKM yang dipilih melalui GPS, selanjutnya jika pengguna memilih pilihan website maka aplikasi akan menampilkan website lokasi UKM yang dipilih melalui web browser, selanjutnya jika pengguna memilih pilihan melihat contact maka aplikasi akan menampilkan pilihan tindakan lengkap menggunakan kontak, telepon, dsb sesuai aplikasi yang mendukung pada perangkat pengguna. selanjutnya jika pengguna memilih pilihan email maka aplikasi akan menampilkan pilihan tindakan lengkap melalui aplikasi email yang mendukung pada perangkat pengguna dan pengguna bisa langsung mengirim pesan melalui email. Dan pengguna bisa memberikan reviews melalui pilihan add review maka aplikasi akan menampilkan form review berupa name, email, review dan memberi nilai berupa range bintang.

Pada Gambar 5 menggambarkan bagaimana proses yang terjadi ketika User Memilih Hiburan. Proses pertama yaitu pengguna akan memilih Hiburan, selanjutnya aplikasi akan menampilkan pilihan kategori Studio foto - fotografi, Rental playstation dan Warnet dan game online, jika pengguna memilih pilihan rental playstation maka aplikasi akan menampilkan lagi pilihan kategori list dan nearby. Begitu pula jika pengguna memilih pilihan Studio foto - fotografi, maka aplikasi akan menampilkan juga pilihan kategori list dan nearby. Jika pengguna sudah memilih salah satu UKM maka aplikasi akan menampilkan about us berupa informasi ringkas tentang UKM tersebut dan menampilkan contact details dari UKM yang dipilih tersebut. Selanjutnya pengguna bisa memasukkan data inquiry yang berisi full name, contact No. , email, city dan message dan pengguna bisa mengirim atau menghapus data inquiry yang dimasukkan, selanjutnya jika pengguna memilih pilihan 
location maka aplikasi akan menampilkan lokasi UKM yang dipilih melalui GPS, selanjutnya jika pengguna memilih pilihan website maka aplikasi akan menampilkan website lokasi UKM yang dipilih melalui web browser, selanjutnya jika pengguna memilih pilihan melihat contact maka aplikasi akan menampilkan pilihan tindakan lengkap menggunakan kontak, telepon, dsb sesuai aplikasi yang mendukung pada perangkat pengguna. selanjutnya jika pengguna memilih pilihan email maka aplikasi akan menampilkan pilihan tindakan lengkap melalui aplikasi email yang mendukung pada perangkat pengguna dan pengguna bisa langsung mengirim pesan melalui email. Dan pengguna bisa memberikan reviews melalui pilihan add review maka aplikasi akan menampilkan form review berupa name, email, review dan memberi nilai berupa range bintang.

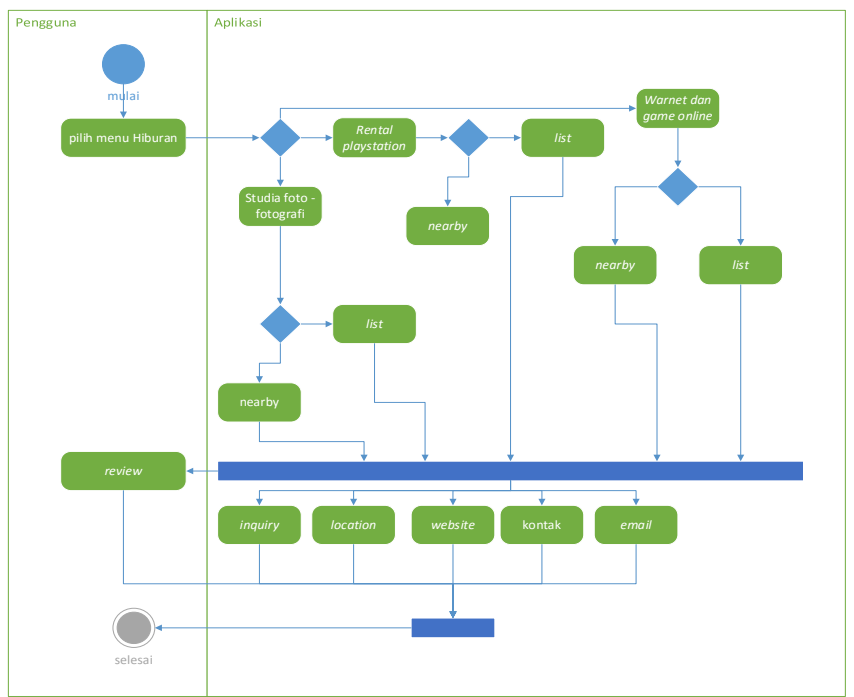

Gambar 5. Activity Diagram Hiburan

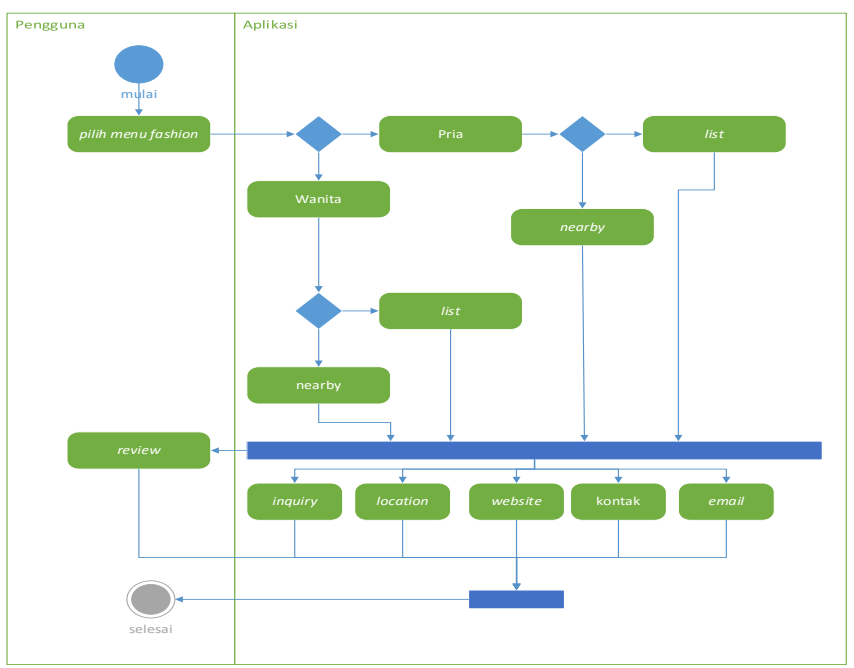

Gambar 6. Activity Diagram Memilih Fashion

Pada Gambar 6 menggambarkan bagaimana proses yang terjadi ketika User Memilih Fashion. Proses pertama yaitu pengguna akan memilih Fashion, selanjutnya aplikasi akan menampilkan pilihan kategori pria atau wanita, jika pengguna memilih pilihan pria maka aplikasi akan menampilkan lagi pilihan kategori list dan nearby. Sedangkan jika pengguna memilih pilihan wanita maka aplikasi akan menampilkan juga pilihan kategori list dan nearby. Jika pengguna sudah memilih salah satu UKM maka aplikasi akan menampilkan

about us berupa informasi ringkas tentang UKM tersebut dan menampilkan contact details dari UKM yang dipilih tersebut. Selanjutnya pengguna bisa memasukkan data inquiry yang berisi full name, contact No. , email, city dan message dan pengguna bisa mengirim atau menghapus data inquiry yang dimasukkan, selanjutnya jika pengguna memilih pilihan location maka aplikasi akan menampilkan lokasi UKM yang dipilih melalui GPS, selanjutnya jika pengguna memilih pilihan website maka aplikasi akan menampilkan website lokasi UKM yang dipilih melalui web browser , selanjutnya jika pengguna memilih pilihan melihat contact maka aplikasi akan menampilkan pilihan tindakan lengkap menggunakan kontak, telepon, dsb sesuai aplikasi yang mendukung pada perangkat pengguna. selanjutnya jika pengguna memilih pilihan email maka aplikasi akan menampilkan pilihan tindakan lengkap melalui aplikasi email yang mendukung pada perangkat pengguna dan pengguna bisa langsung mengirim pesan melalui email. Dan pengguna bisa memberikan reviews melalui pilihan add review maka aplikasi akan menampilkan form review berupa name, email, review dan memberi nilai berupa range bintang.

Diagram kelas merupakan struktur statis yang menggambarkan struktur dari suatu sistem dengan menunjukkan sistem kelas, atribut, operasi, dan hubungan antara objek-objek. Pada diagram kelas dapat dilihat di gambar 6 .

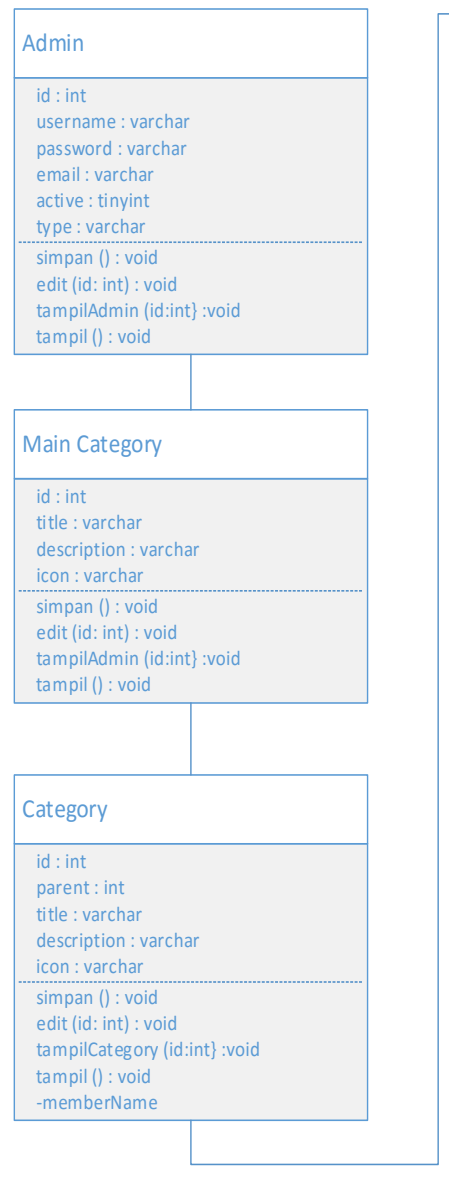

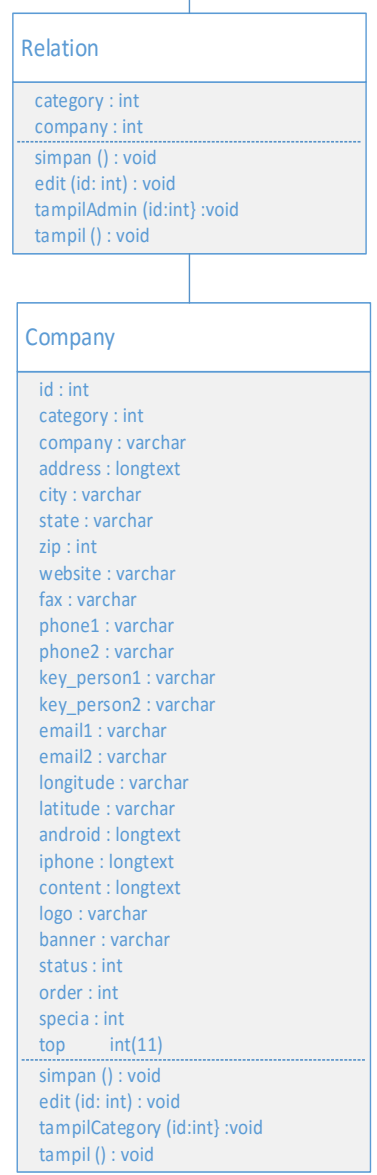

Gambar 7. Class Diagram

\section{IMPLEMENTASI DAN PENGUJIAN}

A. Implementasi Basis Data

Tahapan ini mengimplementasikan hasil dari perancangan basis pada sistem yang telah dibuat sebelumnya. 
Pada tabel k7858524_ukmtembalang, berisi database yang ada pada aplikasi UKM Tembalang. Ada 7 tabel yang terdapat pada k7858524_ukmtembalang, yaitu tabel categories, company, enquries, maincategory, relation, reviews dan users.

Implementasi dari tabel UKM Tembalang pada basis data k7858524_ukmtembalang dapat dilihat pada Tabel 1.

Tabel. 1 Struktur Tabel k7858524_ukmtembalang

\begin{tabular}{|c|c|c|c|c|c|}
\hline 良 & Structure & $\square \mathrm{SQL}$ & Q Search & (1) Query Export & Impor \\
\hline & Table $\Delta$ & Action & & & \\
\hline$\square$ & categories & 国 Browse & Structure & 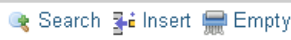 & y $\odot$ Drop \\
\hline$\square$ & company & Browse & If Structure & S Search 할 Insert 最 Empty & y $\odot$ Drop \\
\hline$\square$ & enquries & 圆 Browse & Structure & Search 产t Insert 最 Empty & y $\odot$ Drop \\
\hline$\square$ & maincategory & 囯 Browse & Ie Structure & 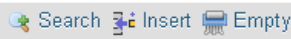 & y $\odot$ Drop \\
\hline$\square$ & relation & 囯 Browse & De Structure & 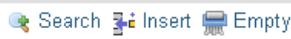 & y $\odot$ Drop \\
\hline$\square$ & reviews & 圂 Browse & Structure & 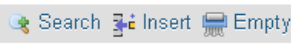 & y $\odot$ Drop \\
\hline$\square$ & user & 圂 Browse & Wef Structure & 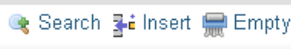 & y $\odot$ Drop \\
\hline
\end{tabular}

Pada Tabel. 2, menampilkan strukrur tabel user. Dimana tabel user ini merupakan tabel yang berisi database dari admnin yang mengatur keseluruhan data yang ada pada basis data k7858524_ukmtembalang.

Tabel. 2. Struktur Tabel Administrator

\begin{tabular}{|c|c|c|c|c|c|c|}
\hline$\leftarrow$ & \multicolumn{6}{|c|}{ 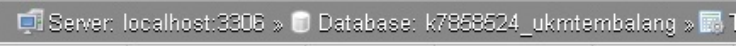 } \\
\hline 圂 & Browse & Structure & $\Xi \mathrm{SQL}$ & Q Search & z̧⿻三丨口 & Insert \\
\hline & \# Name & Type & Collation & Attributes & Null & Default \\
\hline$\square$ & $1 \underline{\text { id }}$ & $\operatorname{int}(11)$ & & & No & Mone \\
\hline$\square$ & 2 username & varchar(60) & latin1_swedis & -ci & No & None \\
\hline$\square$ & 3 password & varchar(60) & latin1_swedis & & No & Mone \\
\hline$\square$ & 4 email & varchar(255) & latin1_swedis & $-\mathrm{ci}$ & No & Mone \\
\hline$\square$ & 5 active & tinyint(4) & & & No & None \\
\hline$\square$ & 6 type & varchar(5) & latin1_swedis & Lci & No & None \\
\hline
\end{tabular}

Pada Tabel. 3 Menampilkan struktur tabel main category pada basis data k7858524_ukmtembalang digunakan untuk menyimpan database kategori utama pada UKM Tembalang.

Tabel. 3 Struktur Tabel Main Category

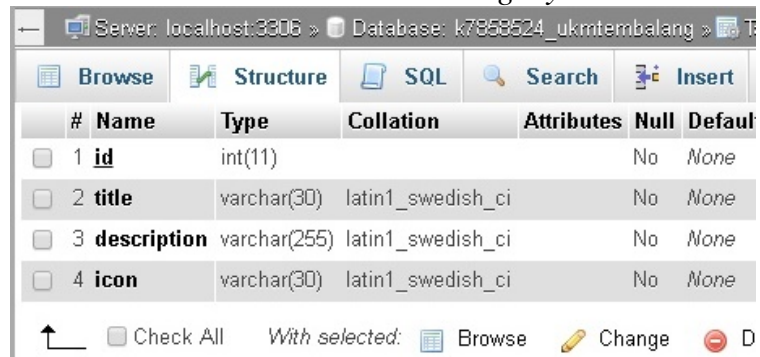

Pada Tabel. 4 Menampilkan struktur tabel Categori yang merupakan tempat menyimpan data - data kategori pada aplikasi UKM Tembalang, semua data kategori yang dimasukkan oleh admin akan tersimpan pada tabel ini, dan ditampilkan pada perangkat bergerak.
Tabel. 4. Struktur Tabel Lokasi

\begin{tabular}{|c|c|c|c|c|c|c|c|}
\hline$\leftarrow$ & \multicolumn{7}{|c|}{ 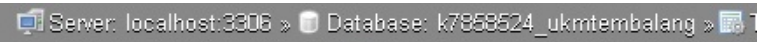 } \\
\hline 囯 & Browse & Structure & $\triangle$ SQL & $Q$ & Search & $\underline{7}$ & Insert \\
\hline & \# Name & Type & Collation & & Attributes & Null & Defaul \\
\hline$\square$ & $1 \underline{\text { id }}$ & int(11) & & & & No & None \\
\hline$\square$ & 2 parent & int(11) & & & & No & Mone \\
\hline$\square$ & 3 title & varchar(300) & latin1_swedi & h_ci & & No & None \\
\hline$\square$ & 4 description & longtext & latin1_swedi & h_ci & & No & Mone \\
\hline$\square$ & 5 icon & varchar(255) & latin1_swedi & h_ci & & No & None \\
\hline
\end{tabular}

Pada Tabel. 5 Menampilkan struktur tabel Company yang merupakan tempat menyimpan data perusahaan UKM yang didaftarkan pada aplikasi UKM Tembalang. Pada database ini admin dapat memasukkan semua data yang berkaitan dengan UKM.

Tabel. 5. Struktur Tabel Company

\begin{tabular}{|c|c|c|c|c|c|c|c|c|c|c|}
\hline 囯 & & owse & al & Structure & $\square \mathrm{SQL}$ & Q 5 & Search & \multicolumn{3}{|c|}{ żt Insert } \\
\hline & $\#$ & Name & & Type & Collatio & & Attribu & es & Null & Defat \\
\hline$\square$ & & id & & $\operatorname{int}(11)$ & & & & & No & None \\
\hline$\square$ & & categor & & $\operatorname{int}(11)$ & & & & & No & None \\
\hline$\square$ & & compar & & $\operatorname{varchar}(300)$ & latin1_sw & dish_ci & & & No & None \\
\hline$\square$ & & address & & longtext & latin1_sw & dish_ci & & & No & Mone \\
\hline$\square$ & & city & & varchar(255) & latin1_sw & dish_ci & & & No & None \\
\hline 0 & & state & & varchar(255) & latin1_sw & dish_ci & & & No & Mone \\
\hline
\end{tabular}

B. Implementasi Antarmuka

Implementasi desain antarmuka merupakan transformasi desain antarmuka aplikasi. Tampilan antarmuka dari aplikasi UKM Tembalang adalah sebagai berikut.

\section{Antarmuka Halaman Utama}

Halaman menu utama pada aplikasi UKM tembalang merupakan tampilan awal pada program, dimana pada halaman ini pengguna dapat melihat tampilan halaman menu utama. Pada saat aplikasi dibuka maka yang akan tampil di perangkat bergerak seperti tampilan pada Gambar 8.

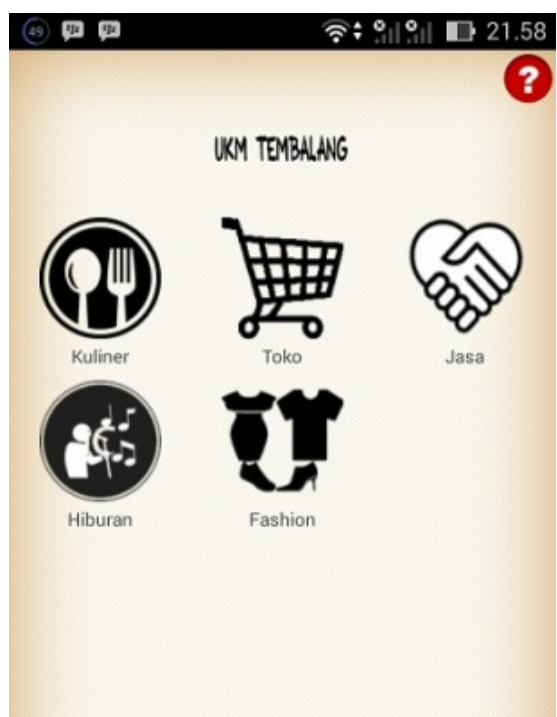

Gambar 8. Halaman Utama 


\section{Antarmuka Halaman kategori}

Pada antarmuka halaman kategori atau antarmuka category merupakan tampilan awal ketika telah memilih salah satu daei menu pada halaman utama. Pada halaman kategori, pengguna akan memilih jenis kategori yang diinginkan. Salah satu implementasi halaman menu kategori dapat dilihat pada Gambar 9.

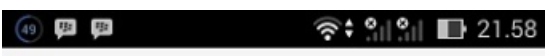

\section{E UKM TEMBLLANG}

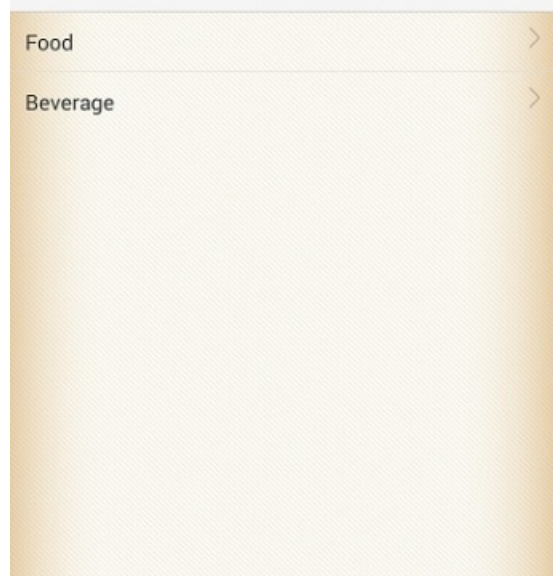

Gambar 9. Halaman Kategori

\section{Antarmuka Halaman Daftar UKM}

Antarmuka halaman UKM akan menampilkan kumpulan daftar UKM yang telah dimasukkan di aplikasi UKM Tembalang. Pengguna bisa memilih melihat pilihan menu pada halaman ini dalam bentuk list, atau pengguna bisa melihat pilihan menu dalam bentuk nearby yang merupakan tampilan untuk UKM yang rekomended pada halaman ini. Untuk tampilan antarmuka halaman daftar UKM dapat dilihat pada Gambar 10.

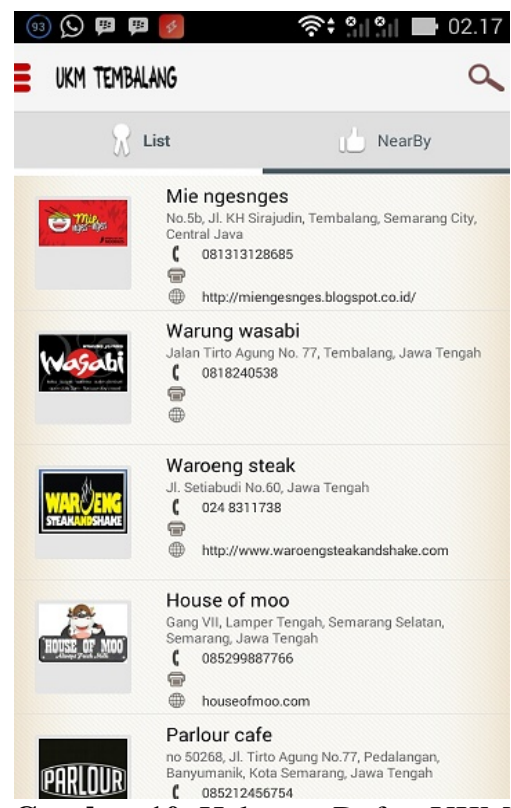

\section{Antarmuka Halaman UKM}

Pada Antarmuka halaman ini, aplikasi akan menampilkan informasi tentang sebuah UKM yang telah terdaftar pada aplikasi UKM Tembalang, mulai dari nama
UKM, banner UKM, alamat, nomor telepon, kode pos, website, fax, dan uraian singkat tentang UKM beserta gambar foto UKM maupun rutinitas yang ada pada sebuah UKM serta tamplian dari review yang telah diberikan oleh pengguna. Tampilan Halaman UKM dapat dilihat pada Gambar 11 dan 12.

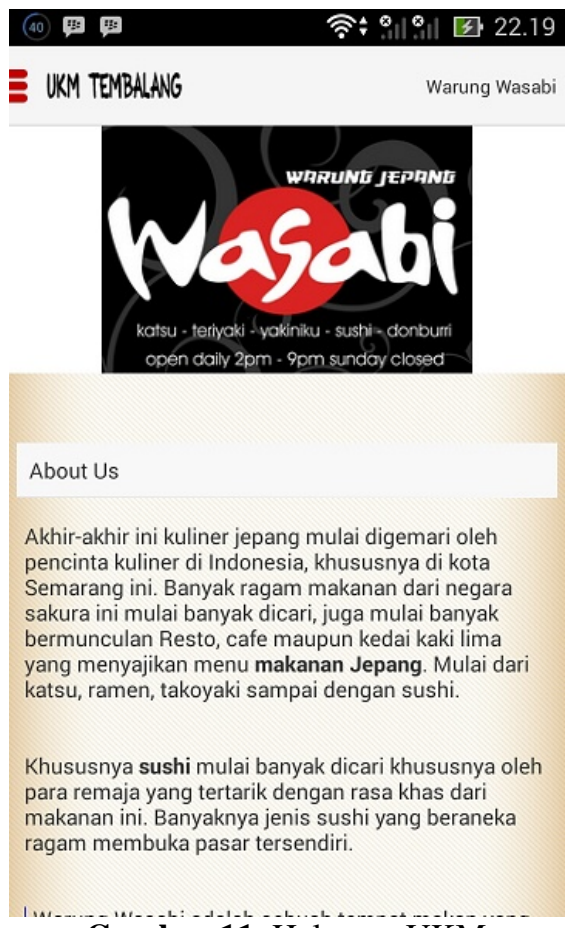

Gambar 11. Halaman UKM

(40)

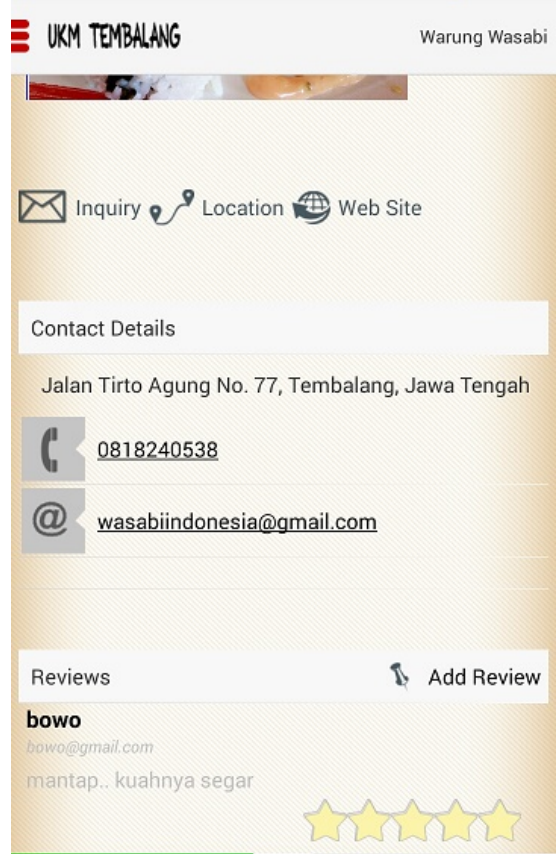

Gambar 12. Halaman UKM

Untuk mencari tahu lokasi UKM melalui maps, pengguna bisa memilih gambar dengan logo dan tulisan location pada aplikasi. Maka kemudian aplikasi akan membuka halaman map yang menunjukkan lokasi antara pengguna dan UKM yang akan dituju. Tampilan halaman lokasi maps dapat dilihat pada Gambar 13. 


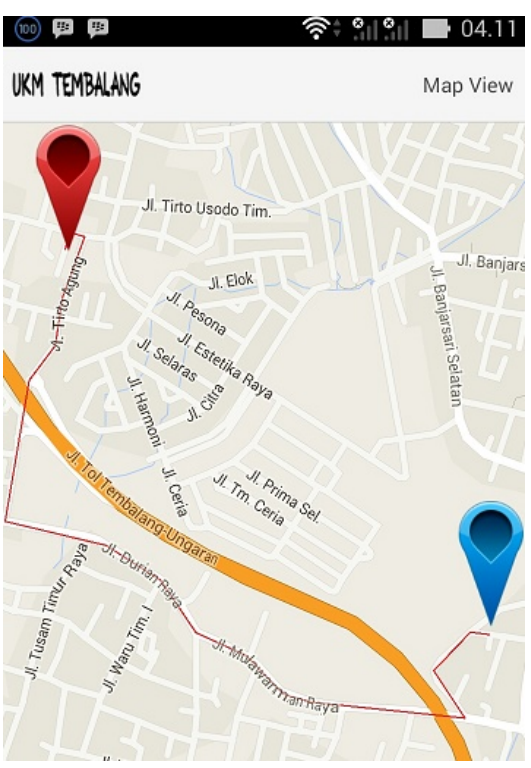

Gambar 13. Tampilan Maps

\section{Antarmuka Halaman Admin}

Halaman Admin pada UKM Tembalang merupakan halaman bagi pengelola aplikasi untuk memasukkan data, mengubah data maupun menghapus data yang akan di tampilkan pada halaman aplikasi UKM Tembalang. Halaman login Admin dapat dilihat pada Gambar 14.

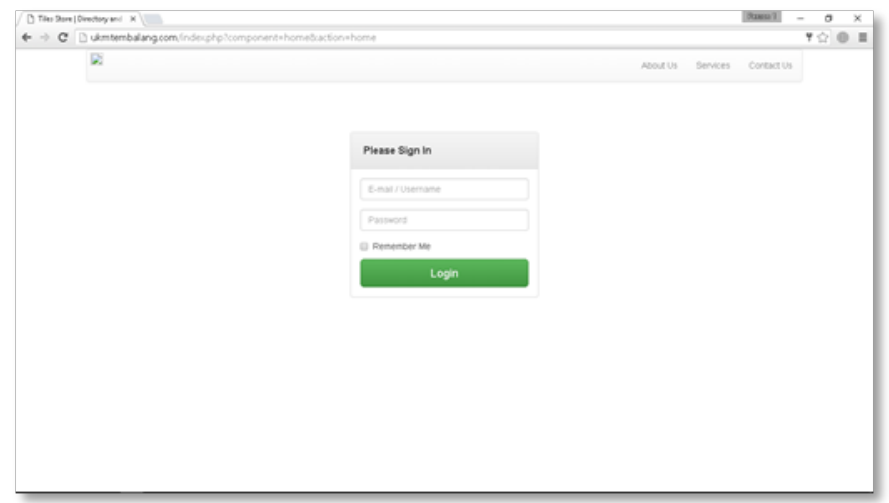

Gambar 14. Halaman Menu Login Admin

\section{Antarmuka Halaman Dashboard}

Menu dash board pada halaman admin merupakan halaman pertama pada bootsrap UKM Tembalang. Di menu dashboard ini berisi halaman Main Category, Category dan Company Registration. Halaman ini berfungsi untuk menambah, mengedit, maupun menghapus data masukan yang akan digunakan pada aplikasi UKM Tembalang. Tampilan menu dash board dapat dilihat pada Gambar 15.

\section{Pengujian}

Pada aplikasi UKM Tembalang pengujian dengan metode blackbox di fokuskan pada keperluan fungsional dari software yang berusaha untuk menemukan kesalahan dalam beberapa kesalahan seperti fungsi aplikasi salah, kesalahan interface, kesalahan struktur data atau akses basisdata,dan kesalahan kinerja. Hasil pengujian dapat dilihat pada Tabel 6.

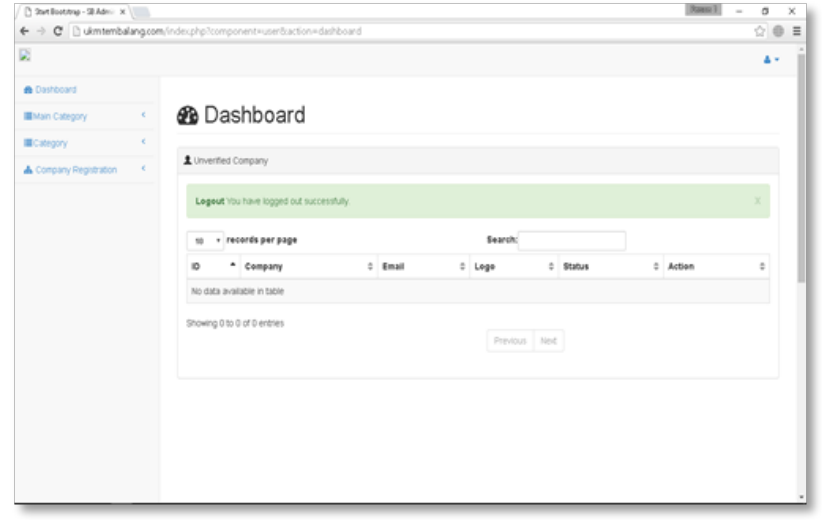

Gambar 15. Halaman Menu Dashboard

Tabel 6 Pengujian Black-box

\begin{tabular}{|c|c|c|c|}
\hline $\begin{array}{c}\text { Nama } \\
\text { Pengujian }\end{array}$ & Bentuk Pengujian & $\begin{array}{c}\text { Hasil Yang } \\
\text { Diharapkan }\end{array}$ & $\begin{array}{c}\text { Hasil } \\
\text { Pengujian }\end{array}$ \\
\hline $\begin{array}{l}\text { Pengujian } \\
\text { aplikasi } \\
\text { UKMTEMB } \\
\text { ALANG.apk }\end{array}$ & $\begin{array}{l}\text { Mengklik aplikasi } \\
\text { UKMTEMBALAN } \\
\text { G }\end{array}$ & $\begin{array}{lr}\text { Muncul tampilan } \\
\text { login } & \text { dari } \\
\text { UKMTEMBALANG }\end{array}$ & Berhasil \\
\hline $\begin{array}{l}\text { Pengujian } \\
\text { Halaman } \\
\text { Utama }\end{array}$ & $\begin{array}{l}\text { Mengklik salah satu } \\
\text { nenu yang ada di } \\
\text { salaman utama }\end{array}$ & $\begin{array}{l}\text { Muncul tampilan list } \\
\text { daftar kategori pada } \\
\text { ralaman Kategori } \\
\text { Muncul tampilan list }\end{array}$ & Berhasil \\
\hline $\begin{array}{l}\text { Pengujian } \\
\text { Halaman } \\
\text { Kategori }\end{array}$ & $\begin{array}{l}\text { Iengklik salah satu } \\
\text { !enu yang ada di } \\
\text { alaman kategori }\end{array}$ & $\begin{array}{l}\text { UKM pada halaman } \\
\text { daftar UKM baik di } \\
\text { halaman List maupun } \\
\text { di halaman NearBy }\end{array}$ & Berhasil \\
\hline $\begin{array}{l}\text { Pengujian } \\
\text { Halaman } \\
\text { UKM }\end{array}$ & $\begin{array}{l}\text { Mengklik salah satu } \\
\text { menu UKM yang } \\
\text { ada di halaman } \\
\text { daftar kategori }\end{array}$ & $\begin{array}{l}\text { Muncul halaman } \\
\text { UKM yang berisi } \\
\text { logo, AboutUs yang } \\
\text { berisi tulisan dan } \\
\text { gambar UKM, menu } \\
\text { Inquiry, menu } \\
\text { Location, menu Web } \\
\text { Site, contact details, } \\
\text { menu reviews dan } \\
\text { menu add review }\end{array}$ & Berhasil \\
\hline $\begin{array}{l}\text { Pengujian } \\
\text { halaman } \\
\text { inquiry }\end{array}$ & $\begin{array}{l}\text { Mengklik menu } \\
\text { inquiry } \\
\text { halaman UKM }\end{array}$ & $\begin{array}{l}\text { Muncul halaman } \\
\text { inquiry, yang berisi } \\
\text { Full Name, Contact } \\
\text { No, Email, City dan } \\
\text { message }\end{array}$ & Berhasil \\
\hline $\begin{array}{l}\text { Pengujian } \\
\text { halaman } \\
\text { Location }\end{array}$ & $\begin{array}{l}\text { Mengklik menu } \\
\text { location pada } \\
\text { halaman UKM }\end{array}$ & $\begin{array}{l}\text { Muncul tampilan map } \\
\text { beserta rute antara } \\
\text { pengguna dan lokasi }\end{array}$ & Berhasil \\
\hline $\begin{array}{l}\text { Pengujian } \\
\text { tombol menu } \\
\text { Web Site }\end{array}$ & $\begin{array}{l}\text { Mengklik menu } \\
\text { Web Site pada } \\
\text { halaman UKM }\end{array}$ & $\begin{array}{l}\text { Muncul browser yang } \\
\text { menampilkan website } \\
\text { dari UKM }\end{array}$ & Berhasil \\
\hline $\begin{array}{l}\text { Mengklik } \\
\text { menu Add } \\
\text { Review pada } \\
\text { halaman } \\
\text { aplikasi }\end{array}$ & $\begin{array}{l}\text { Muncul halaman } \\
\text { pop up baru yang } \\
\text { berisi form Name, } \\
\text { Email, Review, dan } \\
\text { indicator } 5 \text { bintang }\end{array}$ & $\begin{array}{l}\text { Muncul halaman pop } \\
\text { up bawaan perangkat } \\
\text { bergerak, atau } \\
\text { langsung menelepon } \\
\text { nomor kontak UKM } \\
\text { melalui perangkat }\end{array}$ & Berhasil \\
\hline $\begin{array}{l}\text { Pengujian } \\
\text { tombol menu } \\
\text { email }\end{array}$ & $\begin{array}{l}\text { Mengklik menu } \\
\text { email pada halaman } \\
\text { UKM }\end{array}$ & $\begin{array}{l}\text { Muncul halaman pop } \\
\text { up untuk mengirim } \\
\text { email } \\
\text { Muncul halaman Play }\end{array}$ & Berhasil \\
\hline $\begin{array}{l}\text { Pengujian } \\
\text { menu Play } \\
\text { Store }\end{array}$ & $\begin{array}{l}\text { Mengklik menu } \\
\text { Google play pada } \\
\text { halaman UKM }\end{array}$ & $\begin{array}{l}\text { Store Android yang } \\
\text { langsung } \\
\text { mengarahkan ke } \\
\text { alamat aplikasi UKM } \\
\text { di Play Store } \\
\end{array}$ & Berhasil \\
\hline
\end{tabular}




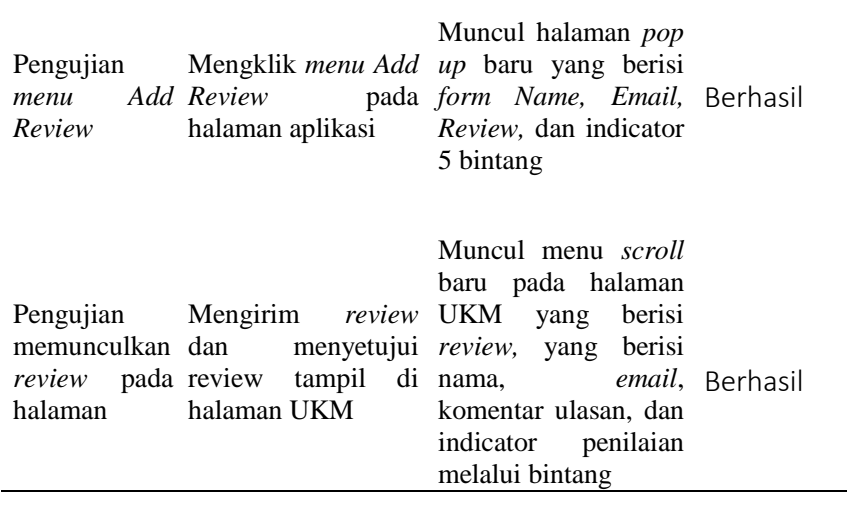

\section{PENUTUP}

Kesimpulan yang dapat diambil dari penelitian yang telah dilakukan pada perancangan Aplikasi UKM Tembalang adalah sebagai berikut.

1. Aplikasi UKM Tembalang sudah dapat digunakan sebagai alternatif untuk media informasi UKM di Tembalang dan sekitarnya.

2. Aplikasi UKM Tembalang sudah dapat digunakan untuk mencari lokasi UKM.

3. Melalui aplikasi UKM Tembalang pengimplementasian Location Based Service (LBS) di Smartphone berbasis android telah berhasil dilakukan.

4. Pengujian aplikasi UKM Tembalang dengan menggunakan black box berhasil sesuai dengan hasil yang diharapkan.

5. Fungsi-fungsi yang terdapat pada aplikasi dapat berfungsi dengan baik dan sesuai dengan fungsionalitas masing-masing.

6. Pembuatan aplikasi berbasis Mobile dengan menggunakan WebView memberikan kemudahan bagi pengembang dalam membuat suatu aplikasi berbasis mobile, karena dengan pemanfaatan WebView aplikasi yang dikembangkan dapat langsung diberikan karakteristik yang dimiliki setiap platform yang berbeda sehingga dalam mengembangkan aplikasi ini hanya cukup membuat satu aplikasi yang dapat dipindahkan langsung ke android atau bahkan Mobile Web Application yang ditempatkan pada Webserver.

Berikut adalah pengembangan yang dapat dilakukan terhadap Aplikasi UKM Tembalang:

1. Perlu dilakukan penelitian lanjutan untuk mengembangkan aplikasi UKM Tembalang pada perangkat bergerak selain Android.

2. Penambahan fitur pada Aplikasi UKM
TEMBALANG masih sangat disarankan, seperti penambahan pilihan menu makanan, navigasi Maps yang lebih baik dan sebagainya.

3. Perlu dilakukan penelitian lebih lanjut bagaimana membuat agar Aplikasi UKM Tembalang dapat berjalan di sistem operasu seperti Blackberry, IOS dan Windows Phone.

4. Perlu dilakukan penelitian lebih lanjut agar Aplikasi UKM Tembalang dapat dikembangkan hingga menjadi salah satu Market Place yang fiturnya lebih lengkap dari yang ada pada aplikasi UKM Tembalang saat ini.

\section{DAFTAR PUSTAKA}

[1] Tambunan, Tulus T.H., 2009. UMKM di Indonesia. Ghalia Indonesia. Jakarta.

[2] Budi Yulianto, dan Rita Layona, “Aplikasi Pencarian Tempat Wisata Berbasis GPS dengan Metode Radius dan Rating”, Jurnal ComTech, 6(1), 2015.

[3] Agus Sucista, "Pembangunan Sistem Aplikasi Layanan Berbasis Lokasi Pencarian ATM dan Pom Bensin Terdekat Berbasis Android”, Sekolah Tinggi Manajemen Informatika dan Komputer, Amikom, Yogyakarta, 2012.

[4] Rita Layona, dan Budi Yulianto. APLIKASI PENCARIAN INFORMASI DAN LOKASI TEMPAT MAKAN PADA PERANGKAT MOBILE BERBASIS ANDROID. Jurnal Teknologi Dan Sistem Informasi, 2(2), 9-16, 2016.

[5] I Gusti Putu Deviara Putra, "Perancangan Simulasi Sistem Informasi Transportasi Bus Trans Sarbagita Dengan Menggunakan Metode Location Basec Service Berbasis Mobile”, Ilmu Komputer Universitas Udayana, Bali, 2014.

[6] Satyaputra, Alfa., dan Aritonang, E.V., Java For Beginners With Eclipse 4.2 Juno, Elex Media Komputindo, Jakarta, 2014

[7] Ladjamudin, Al Bahra Bin. 2007, Analisis dan Desain Sistem Informasi, Penerbit Graha Ilmu

[8] H, Nazruddin Safaat, Pemrograman Aplikasi Mobile Smartphone dan Tablet PC Berbasis Android, Informatika, Bandung, 2012.

[9] Google Developers, 2014, Google Maps JavaScript Api V3. [Diakses Tanggal 28 Januari 2014]. http://developers.google.com/maps/documentation/j avascript/

[10] Google Maps API, http://library.binus.ac.id/eColls/eThesisdoc/Bab2HT ML/2012100267ifbab2/page31.html, 29 January 2014 (29 January 2014) 
